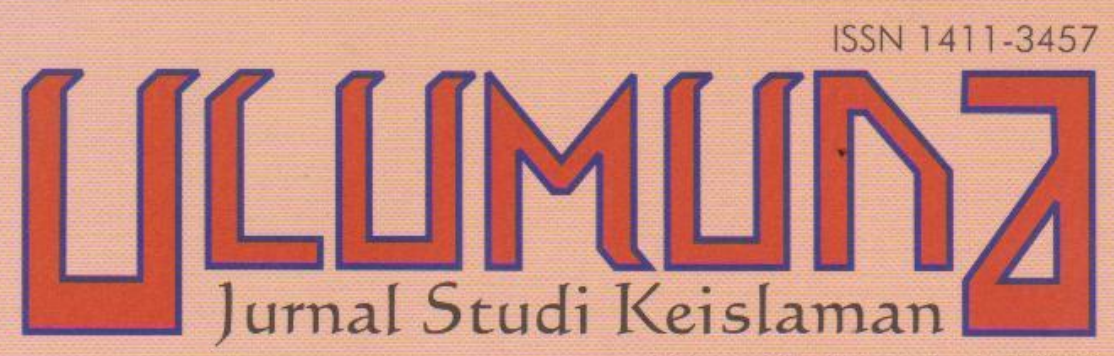

Volume XII• Nomor 1• Juni 2008

STUDI ANALITIS DIMENSI SACIFACT PENDIDIKAN ISLAM PADA MASA KEJAYAANNYA (750-1258 M) Abdul Fattah

AKTUALISASI MANUSIA VERSI AL-QUR'AN: ANTARA IDEALITAS DAN REALITAS PENDIDIKAN ISLAM Ismail Thoib

PENDIDIKAN ISLAM DAN PENCERAHAN SPIRITUALITAS: IKHTIAR MENJAWAB TANTANGAN POSMODERNISME Suparta

LESSON STUDY DALAM PEMBELAJARAN AGAMA ISLAM DI SEKOLAH UMUM Ahmad Munjin dan Khoirul Adib

STUDI PERUBAHAN KELEMBAGAAN DAN METODOLOGI PADA MADRASAH MODEL Taufik Churahman dan Musfigon POSISI PEREMPUAÑ
PERSPEKTIF ULAMA KLASIK
Baehaqi 


\section{PEDOMAN TRANSLITERASI}

\begin{tabular}{|c|c|c|c|}
\hline Arab & Latin & Arab & Latin \\
\hline 1 & $=$ & ف & $=\mathbf{f}$ \\
\hline ب & $=$ & ق & $=\mathrm{q}$ \\
\hline$\dot{H}$ & ts & ك & $=\mathbf{k}$ \\
\hline ج & $=$ & $J$ & $=1$ \\
\hline$\tau$ & $=$ & b & $=\mathrm{m}$ \\
\hline$\dot{\tau}$ & $=\quad \mathrm{kh}$ & $\dot{0}$ & $=\mathbf{n}$ \\
\hline$د$ & $=$ & و - - - 1 & $=\mathbf{w}$ \\
\hline$\dot{j}$ & $\mathrm{dz}$ & • & $=h$ \\
\hline$\jmath$ & $=$ & $\&$ & $=$, \\
\hline j & $=$ & ي & $=y$ \\
\hline س س & $=$ & & \\
\hline ش & $=$ & \multirow{2}{*}{\multicolumn{2}{|c|}{$\begin{array}{l}\text { Untuk Madd } \\
\text { dan Diftong }\end{array}$}} \\
\hline ص & sh & & \\
\hline ض & dl & i & $=$ â (a panjang) \\
\hline b & th & إين & $=\hat{\mathbf{1}}(\mathbf{i}$ panjang) \\
\hline ظ & $\mathrm{zh}$ & أوْ & $=\quad \hat{\mathbf{u}}$ (u panjang) \\
\hline$\varepsilon$ & $=$ & 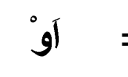 & $=a w$ \\
\hline$\dot{\varepsilon}$ & $=g h$ & آين & $=$ ay \\
\hline
\end{tabular}




\section{ISI}

TRANSLITERASI

ANTARAN

UTAMA

Abdul Fattah

Studi Analitis Dimensi Sacifact Pendidikan Islam pada Masa Kejayaannya $(750-1258 \mathrm{M}) \bullet 1-28$

Ismail Thoib

Aktualisasi Manusia Versi Al-Qur'an:

Antara Idealitas dan Realitas

Pendidikan Islam • 29-46

Suparta

Pendidikan Islam dan Pencerahan

Spiritualitas: Ikhtiar Menjawab Tantangan

Posmodernisme • 47-66

Ahmad Munjin Nasih Lesson Study dalam Pembelajaran

dan Khoirul Adib Pendidikan Agama Islam

di Sekolah Umum • 67-88

Taufik Churahman Dinamika Pendidikan Islam: Studi

dan Musfiqon

Perubahan Kelembagaan dan Metodologi

pada Madrasah Model • 89-106

LEPAS

Mutawalli Pembaruan Hukum Islam:

Menimbang Tawaran Pemikiran

'Abd al-Lâh al-Na'îm • 107-128

Baehaqi Posisi Perempuan

Perspektif Ulama Klasik • 129-142

Ahmad Sulhan Islam Kontemporer: Antara Reformasi

dan Revolusi Peradaban • 143-156

Ahmad Choirul Rofiq Menilai Kompetensi al-Mâturîdî di Bidang

Tafsir al-Qur'an • 157-182

ULAS BUKU

Yayuk Fauziyah Menyingkap Kuasa Maskulinitas di Balik

Tabir Feminitas Wanita Jawa • 183-200

INDEKS 


\title{
POSISI PEREMPUAN \\ PERSPEKTIF ULAMA KLASIK
}

\author{
Baehaqi* $^{*}$
}

\begin{abstract}
One of the Islamic facets that attracts much attention and provokes debates among Muslim intellectuals is discourse of women's position in classical Islamic doctrines: women's position in private and public areas. Women are often seen as peripheral, second class citizen, marginal and victims of injustice constructed by society's perceptions. Considering that, classic Muslim scholars are mainly blamed for women inequality because of their interpretation on Al-Qur'an and Hadis. Consequently, societies often view that women's tasks are limited to domestic areas: kitchen, well, and bed. Therefore, Muslim thinkers should reinterpret Al-Qur'an and Hadis focusing on Islamic spirits that emphasize Islam as rabmat for all people, women and men, in all aspects of life.
\end{abstract}

Keywords: Posisi, Ulama Klasik, Perempuan, Ayat al-Qur'an, Hadis

ISLAM oleh setiap muslim dipandang sebagai agama wahyu yang menempatkan al-Qur'an dan hadis sebagai sumber primer dalam membaca persoalan kemanusiaan; politik, ekonomi, budaya, ideologi, keilmuan, dan lainnya. Hal ini mengindikasikan holistisitas dan kekuatan moral nilai-nilai substantif al-Qur'an yang mampu merespons zaman. Boleh dikatakan, nyaris tidak ada satu persoalanpun yang tertinggal dari teropong Islam yang kemudian mengundang polemik.

*Penulis adalah dosen Fakultas Tarbiyah IAIN Mataram, Jln. Pendidikan 35 Mataram. email: dhani_care@yahoo.com 
Salah satu wajah teologis Islam yang menarik perhatian dan sekaligus menarik energi perdebatan kalangan intelektual Islam adalah diskursus atau wacana tentang posisi kaum perempuan dalam doktrin Islam klasik; posisi perempuan dalam ranah publik dan privat. Untuk menelaborasi hal ini, tulisan ini akan mendeskripsikan pandangan ulama klasik terkait dengan posisi dan kedudukan perempuan.

\section{Posisi Perempuan: Tafsiran Ulama Klasik}

Istilah posisi mengindikasikan sesuatu yang menentukan bagi keberadaan seseorang dalam kehidupannya, baik sebagai individu maupun sebagai sebagai kelompok masyarakat. Pengakuan atas identifikasi posisi tersebut yang dikembangkan oleh opini masyarakat dapat berimplikasi positif sekaligus negatif. Dalam konteks perempuan, tema yang akan dipanggul dalam tulisan ini, perempuan acapkali diposisikan sebagai makhluk periferal, kelas dua, marjinal, dan selalu menjadi korban ketidakadilan dari konstruksi yang dibangun oleh opini masyarakat tersebut. Terkait dengan hal ini, ulama klasik menjadi tertuduh utama atas timpangnya posisi kaum Hawa, yang merupakan buah dari produksi dan reproduksi makna yang ditawarkan oleh para ulama klasik atas al-Qur'an dan hadis. Paling tidak, ada tiga ayat al-Qur'an dan beberapa hadis yang melahirkan tafsir misoginis sehingga perempuan seakan-akan hanya menjadi makhluk setengah makhluk. Ayat al-Qur'an pertama yang dirujuk adalah ayat yang berbicara tentang asal kejadian manusia pertama, lebih tepatnya perempuan pertama, yang bernama Hawa yang menjadi pasangan Nabi Adam as. Menurut para mufasir klasik, perempuan merupakan turunan kaum laki (tulang rusuk nabi Adam). Hal ini didasarkan pada penafsiran atas al-Qur'an surat al-Nisâ' (4):1 yang berbunyi:

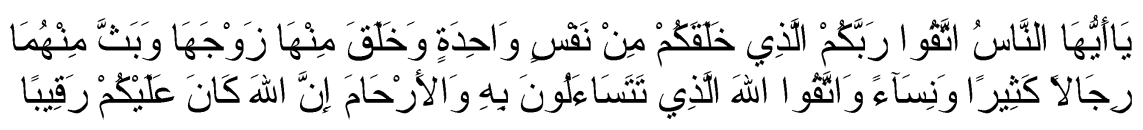


Artinya: "Wahai sekalian manusia! Bertakwalah kepada Tuhan kamu yang telah menjadikan kamu (bermula) dari diri yang satu (Adam), dan yang menjadikan daripada (Adam) itu pasangannya (Hawa), dan juga yang membiakkan dari keduanya lelaki dan perempuan yang ramai. Dan bertakwalah kepada Allah yang kamu selalu meminta dengan menyebut-sebut nama-Nya, serta peliharalah hubungan (silaturrahim) kaum kerabat karena sesungguhnya Allah sentiasa memerhati (mengawas) kamu."

Sebagian besar para penafsir klasik menafsirkan kata nafs wâhidah ditafsirkan dengan arti Nabi Adam sehingga Hawa adalah turunan (derivasi) Nabi Adam. Kalangan penafsir klasik itu adalah semisal al-Thâbârî (w. 310 H.), al-Zamakhsyarî (w. 538 H.), al-Qurthûbî (w. 671 H.), Ibn Katsîr (w. 774 H.), Jalâl al-Dîn al-Sayûthî (w. 911 H.). Al-Thabrâsyî (mufasir Syi’ah) berpendapat bahwa seluruh penafsir sepakat bahwa yang dimaksud dengan "nafs" dalam ayat itu adalah Nabi Adam. Dasar itu, kata jawzaha berarti pasangan Nabi Adam sendiri yang berasal dari Adam sendiri. ${ }^{1}$ Penafsiran itu berimplikasi kepada adanya opini negatif bagi perempuan, yaitu ia selalu dalam genggaman atau di bawah laki-laki. ${ }^{2}$ Hadis yang diacu adalah:

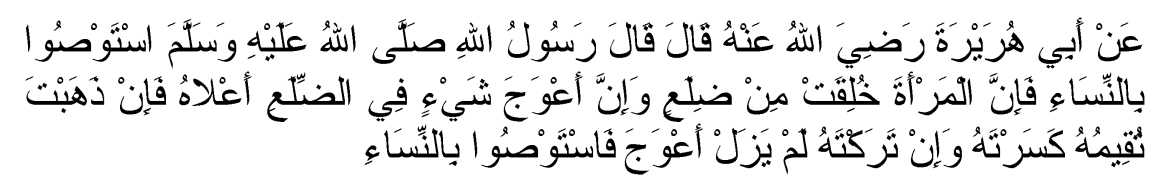

${ }^{1}$ Said Agil Husen al-Munawar, Al-Qur'an Membangun Tradisi Kesalehan Hakiki (Jakarta: Ciputat Press, 2002), 225. Sementara itu, sebagian ulama menafsirkan bahwa kejadian Hawa dan Adam dari satu jenis, seperti yang dikemukakan oleh seperti al-Asfahânî, Sayyid Quthb, dan alThabathabâ'̂̀'. Lihat keterangan Abû Muslim al-Asfahânî, Majma' Mufradât li alfâzh al-Qur'ân al-Karîm, 1976), Sayyid Quthb, Fi Dzhilâl al-Qur'ân, Jilid IV (Beirut: Dâr al-Fikr, 1987), 236; al-Thabathabầî, Al-Mizân fî̀ Tafsîr alQur'ân (Beirut: Muassasah li al-'Alâmî, 1983). Dalam hal ini, para penafsir Indonesia, seperti Halim Hasan dkk. Dalam Tafsir al-Qur'an al-Karim; Hamka, Tafsir al-Azhar; Hasbi al-Shiddiqiy, Tafsir al-Bayan dan al-Nur.

${ }^{2}$ M. Quraisy Shihab, Tafsir al-Mishbah (Jakarta: Lentera Hati, 2000), 314. 
Artinya: "Dari Abû Hurayrah ra., Rasulullah pernah bersabda: nasihatilah perempuan karena mereka diciptakan dari tulang yang bengkok, dan sesungguhnya sebengkok sesuatu dalam tulang adalah paling atas. Oleh karena itu, jika engkau berprinsip selalu ingin meluruskannya maka engkau mematahkannya. Tapi bila engkau membiarkannya, maka ia akan tetap bengkok seperti semula. Karena itu saling nasihatilah kalian".3

Para ulama klasik memahami hadis di atas secara harfiah, yaitu perempuan berasal dari tulang rusuk Nabi Adam yang bengkok, bukan secara metaforis, sehingga ada makna lain yang terkandung di dalamnya. Orang yang memahami hadis di atas dengan makna metaforis menyatakan bahwa hadis ini bertujuan untuk mengingatkan para laki-laki agar menghadapi perempuan dengan bijaksana. Hal ini dikarenakan sifat dan kodrat bawaan mereka berbeda dengan kaum laki-laki sehingga bila tidak disadari akan mengantar laki-laki kepada sikap yang tidak wajar. Tidak ada yang mampu mengubah kodrat bawaan itu, kalaupun ada yang berusaha, maka akibatnya akan fatal laiknya meluruskan tulang rusuk yang bengkok. ${ }^{4}$ Pandangan negatif tentang perempuan ini menjadi pembenaran bagi dominasi lakilaki dalam keluarga yang menyeret terjadinya kekerasan dalam rumah tangga.

${ }^{3}$ Al-Bukhariy, Shahîih al-Bukhârî (Beirut: Dâr al-Fikr, t.t.), hadis ke 3084 . Nilai hadis ini adalah marfû', artinya hadis ini sampai kepada Rasulullah melalui beberapa sanad. Hadis yang senada sebagai pendukung dengan redaksi tidak jauh berbeda dalam al-Turmudzî, Sunan al-Turmudzî (Beirut: Dâr Ihyâ' al-Turâst al-Arabî, t.t.), hadis no. 1083. Demikian juga didukung oleh hadis yang ada Ibn Mâjah, Sunan Ibn Mâjah (Beirut: Dâr al-Fikr, t.t.), hadis ke 1841; lihat pula dalam Muslim, Sḥhâîh Muslim (Beirut: Dâr al-Fikr, t.t.), hadits ke 67. Hadis di atas sejalan dengan bunyi kitab Perjanjian lama pasal II ayat 21-22 yang berbunyi: “....Maka didatangkan Tuhan atas Adam itu tidur yang lelap lalu tidurlah ia, maka diambil Allah sebilah tulang rusuknya lalu ditutupkannya pula tempat itu dengan daging. Maka dari pada tulang yang telah dikeluarkan dari Adam itu diperbuat Tuhan seorang perempuan.

${ }^{4}$ Ibid. 
Ayat kedua al-Qur'an yang paling sering dikemukakan orang untuk mencari pembenaran posisi perempuan adalah ayat alQur'an yang menyatakan bahwa laki-laki adalah Qawwâm atas perempuan, yaitu surat al-Nisâ' (4:34):

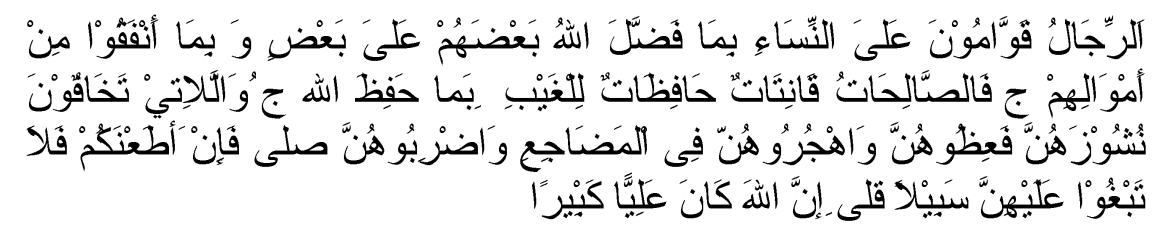

Artinya: "Kaum laki-laki itu adalah pemimpin bagi kaum wanita karena Allah telah melebihkan sebagian mereka (laki-laki) atas sebagian yang lain (wanita), dan karena mereka (laki-laki) telah menafkahkan sebagian dari harta mereka. Sebab itu, wanita yang saleh ialah yang taat kepada Allah lagi memelihara diri ketika suaminya tidak ada, oleh karena Allah telah memelihara (mereka). Wanita-wanita yang kamu khawatirkan nusyuznya, maka nasihatilah mereka dan pisahkanlah mereka di tempat tidur mereka, dan pukullah mereka. Kemudian jika mereka mentaatimu, maka janganlah kamu mencari-cari jalan untuk menyusahkannya. Sesungguhnya Allah Maha Tinggi lagi Maha Besar".

Sebelum lebih jauh dipahami kandungan ayat di atas menurut ulama klasik, maka perlu diketahui terlebih dahulu latar belakang turunnya. Secara historis, para ulama memberikan informasi bahwa ayat ini turun disebabkan oleh adanya seorang laki-laki yang menampar isterinya. Isterinya mengadukan hal tersebut kepada Nabi, dan Nabi memberikan keputusan agar laki-laki itu diberikan hukuman qishâs sesuai dengan perbuatannya. Ketika putusan itu ditetapkan Nabi, maka turunlah ayat di atas sebagai teguran sehingga Nabi menarik kembali keputusannya, dengan demikian laki-laki dengan tidak diqishâs (ditampar). ${ }^{5}$ Teguran itu mengisyaratkan bahwa al-Qur'an melalui ayat di atas berpihak terhadap laki-laki. Dari itu, tidak mengherankan apabila para

5Syihâb al-Dîn Abî al-Fadhal Aḥmad bin 'Âlî, al-Ajab fî Bayân al-Asbâb, Jilid II (Beirut: Dâr Ibn al-Jawzy, 1997), 868; al-Sayûthî, al-Durar alMansyûr, Jilid II (Beirut: Dâr al-Fikr 1993), 512. 
penafsir klasik memberikan penafsiran mendukung hegemoni laki-laki atas perempuan.

Kata قوّ"امون merupakan bentuk plural dari kata قون yang berati "orang-orang yang bertanggungjawab" (al-mutakallafun bi al-amr), baik diikuti oleh huruf "ala" dan "Ba". ${ }^{6}$ Yang menjadi pertanyaan kemudian, apakah kata qawwâmûn hanya laki-laki ataukah juga perempuan. Ibn Katsîr mengatakan: ${ }^{7}$

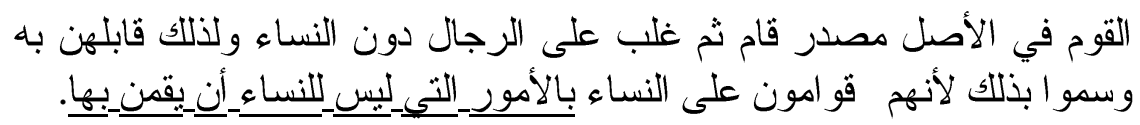

Ungkapan di atas menegaskan bahwa laki-laki dapat melakukan urusan-urusan yang memang semestinya hanya urusan laki-laki dan bukan oleh perempuan. Sementara itu, alLûsî memberikan informasi bahwa kata qawwâmûm bukan ditujukan kepada laki-laki saja, melainkan juga kepada perempuan karena pengungkapan kata qawwâmûm kadang tidak terbatas pada laki-laki saja, seperti kata kata Qawm Fir'aun, Qawm A'ad, dan lain-lain. ${ }^{8}$ Karena itu, yang mesti bertanggungjawab juga terhadap urusan keluarga adalah laki-laki dan perempuan di mana pada saat suami pergi yang bertanggungjawab adalah isteri, dan sebaliknya. Sebagian ulama memberikan tafsiran kata qawwâmûm adalah sebagai pemimpin sehingga posisi laki-laki adalah pemimpin dan perempuan adalah yang dipimpin, sebagaima redaksi ayat al-Qur'an

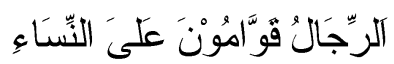

Posisi bagi laki-laki ini sebagai pemimpin diperkuat oleh dua redaksi berikutnya, yaitu:

'Ibn al-Manzhûr, Lisân al-'Arab, Jilid XII (Beirut: Dâr al-Shadir, t.t.), 503.

${ }^{7}$ Ibid.

${ }^{8}$ Muhhammad al-Lûsî, Rûh al-Ma'ânî fi Tafsîr al-Qur'ân al-Azhim wa alSaba' al-Mastanî (Beirut: Dâr Ihyâ’ al-Turâst al-'Ârabî, t.t.). 


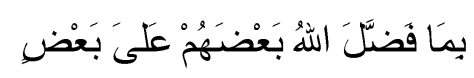

dan

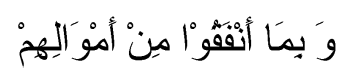

Dua kalimat itu menunjukkan laki-laki lebih utama dibandingkan perempuan. Redaksi pertama menunjukkan kelebihan itu bersifat natural (وهبي) dan kedua karena usaha (كسبى), seperti kelebihan akal, kuat dalam bekerja, sebagai nabi, imam shalat, ikut perang, sebagai saksi, kelebihan dalam pewarisan, dan lain-lain, demikian tafsiran al-Baidlâwî. ${ }^{9}$ Tafsiran yang sama juga dikemukan oleh Ibn Katsîr, bahkan menurutnya, laki-laki itu lebih baik dari perempuan. ${ }^{10}$ Lebih jauh lagi, al-Qurthûbî menyatakan, hak menjadi hakim, pemerintahan, dan perang berada pada laki-laki, bukan perempuan, ${ }^{11}$ selain itu juga laki-laki berkewajiban memberikan mahar serta memenuhi kebutuhan isteri sehingga berhak mendrive istrinya. ${ }^{12}$ Lebih ekstrim lagi adalah pandangan Abû Su'ûd yang menegaskan-dikutip al-Shabûnî-dalam menafsirkan ayat di atas, bahwa perempuan tidak boleh menjadi pemimpin baik dalam skala besar maupun kecil. ${ }^{13}$

${ }^{9}$ Al-Baidlawî, Tafsîr al-Baidlawî (Beirut: Dâr al-Fikr, 1996).

${ }^{10} \mathrm{Ibn}$ Katsîr, Tafsîr al-Qur'an al-Azhîm (Beirut: Dâr al-Fikr, 1401 H.).

11Al-Qurthûbî, al-Jami’ lî Ahkkâm al-Qur'‘an (Mesir: Dâr al-Sya'ab, 1372 H.).

12Al-Thabârî, Jami’ al-Bayân 'an Ta'wîl Âyâh al-Qur'ân (Beirut: Dâr alFikr, 1405 H.). Penafsiran yang semisal dikemukakan oleh al-Wahîîi dan alJawzý bahwa laki-laki dibebani untuk mengatur hak perempuan karena lakilaki dapat bertindak dalam shalat Jum'at, khilafah, pemerintahan, perang, dan menjatuhkan thalak. Al-Nasâfî selanjutnya memberikan penafsiran yang sama dengan penafsiran sebelumnya, ${ }^{12}$ termasuk al-Kiyâ al-Harasî. Lihat misalnya dalam, al-Wahîdî, al-Wajî̀z fî Tafsîr al-Kitâb al-'Azîz (Beirut: Dâr alSyamiyah, $1415 \mathrm{H}$ ); al-Jawzî, Zad al-Masir fî 'Ilm al-Tafsîr (Beirut: al-Maktab al-Islâmî, 1404 H.); al-Nasâfî, Al-Nasâfî (t.tp.: t.np, t.t.); Kiyâ Harâsi, Ahkâm al-Qur'ân (Beirut: Dâr al-Kutub al-Ilmiyah, 1985).

${ }^{13} \mathrm{Al}-S h a b u ̂ n \hat{,}$ Shafwah al-tafâsir (Beirut: Dâr al-Fikr, t.t.). 


\section{Hegemoni Laki-laki: Sebuah Penegasan}

Dengan penafsiran yang telah meletakkan superioritas lakilaki atas perempuan, membuat para feminisme merasa keberatan karena akan berakibat kepada sempitnya ruang dan gerak kaum perempuan yang selalu di bawah penguasaan laki-laki. Salah satu contoh adalah harus adanya izin laki-laki kepada isteri bila ia keluar, walau sekedar menjenguk orangtua, dan lainnya. Penafsiran sedemikian ketat itu barangkali yang ditolak oleh kaum feminis muslim seperti Amina Wadud, Ashgar Ali Engineer, dan lain-lain.

Kesimpulan ulama bahwa laki-laki sebagai pemimpin atas perempuan didukung oleh redaksi dua kalimat seterusnya:

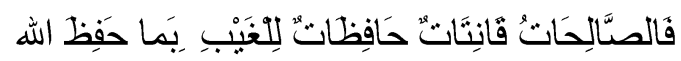

Kata "qânitât" ditafsirkan dengan makna taat, tentunya kepada suami dalam hal kebaikan, dan "al-ḩafizhât" ditafsirkan dengan makna memelihara harta dan kehormatan, yaitu harta benda dan rahasia mereka. ${ }^{14}$ Walaupun perempuan sebagai "anak buah" dan lelaki sebagai pemimipin dalam rumah tangga, akan tetapi mereka saling memiliki hak dan kewajiban sehingga laki-laki tidak semena-mena terhadapnya. Adanya hak dan kewajiban suami-isteri (dalam rumah tangga) dikarenakan memang posisi laki-laki lebih tinggi dibandingkan perempuan sesuai dengan firman Allah surat al-Baqarah (2:28), yaitu:

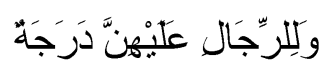

Derajat yang dimaksudkan di sini adalah kepemimpinan lakilaki atas perempuan. Kepemimpinan dalam sebuah kelompok adalah penting, lebih-lebih dalam hal rumah tangga yang merupakan madrasah pertama, yang membutuhkan person yang bertindak sebagai manajer agar dapat berjalan sesuai dengan tujuan perkawinan. Dalam lembaga perkawinan (baca:

14Sayyid Sabbiq, Fiqh al-Sunnah, Jilid II (Beirut: Dâr al-Fikr, 1992), 160. 
rumahtangga), hak itu terbagi menjadi tiga bagian: pertama, hak penuh perempuan yaitu: a) hak mendapat harta berupa mahar dan nafkah (hak materi), perlakuan baik, mendapat rasa aman, pemenuhan kebutuhan biologis (hak non materi). Kedua, hak penuh laki: a) dapat ditaati dalam hal kebaikan; b) dapat menjaga diri dan harta; c) dapat berlaku jujur; d) dapat menampakkan rasa senang terhadap suaminya dan tidak menampakkan wajah cemberut dan dan lain-lainnya. Ketiga, hak bersama, yaitu: a) hak digauli dengan baik, b) saling memiliki warisan semata karena akad nikah, sekalipun perempuan belum sempat digauli; c) hak penisbahan anak kepada mereka; d) hak merasa senang di antara mereka dengan saling memberikan kebutuhan biologis.

Selain al-Qur'an yang menjadi perhantian ulama untuk mencari pembenaran posisi inferioritas perempuan adalah hadis: "Tidaklah akan berjaya suatu kaum (bangsa) yang menyerahkan urusan mereka kepada kaum perempuan". ${ }^{15}$ Hadis ini oleh para penafsir yang bias gender sering menjadikannya sebagai alasan pelarangan kaum perempuan berperan dalam publik, seperti hak berpolitik, menjadi pemimpin, hakim, dan sebagainya. Hal ini sudah menjadi opini publik yang tertuang dalam berbagai kitab fiqh, seperti pendapat para ulama bahwa perempuan tidak pantas menjadi hakim. ${ }^{16}$ Pandangan yang sama dikemukakan oleh Ibn Dhuyan dan Ibn Qudâmah, dengan ungkapannya yang cukup tandas: ${ }^{17}$

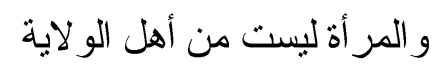

${ }^{15} \mathrm{Al}$-Bukhârî, al-Jami' al-Sḥhahîh al-Mukhtashar, Jilid IV (Beirut: Dâr Ibn Katsîr, 1987), 610; al-Turmudzî, Sunan al-Turmudzî, Jilid IV (Beirut: Dîr Ihyâ' al-Turâts al-'Arabî, t.t.). hadis tersebut dianggap hasan dan shahâîh, tetapi gharîb karena sanadnya hanya seorang saja..

${ }^{16}$ Abû Ishâq, al-Mabda' fî Syarh al-Muqna', Jilid X (Beirut: al-Maktab alIslâmî, 1400 H.), 19.

${ }^{17}$ Idrîs al-Buhtî, Kisyaf al-Iqnâ' 'an Matn al-Iqnâ (Beirut: Dâr al-Fikr, 1405 H.). 
dan pelarangan perempuan menjadi hakim atau pemimpin karena ia kurang akalnya.

Selain hadis dan ayat di atas, sebagian ulama klasik juga memberikan batasan ruang lingkup terhadap perempuan sehingga ia harus berada di dalam rumah saja dan tidak boleh keluar kecuali dalam keadaan emerjensi. Mereka melandaskan pemikiran itu pada firman Allah, dalam surat al-Ahzâb (33):33:

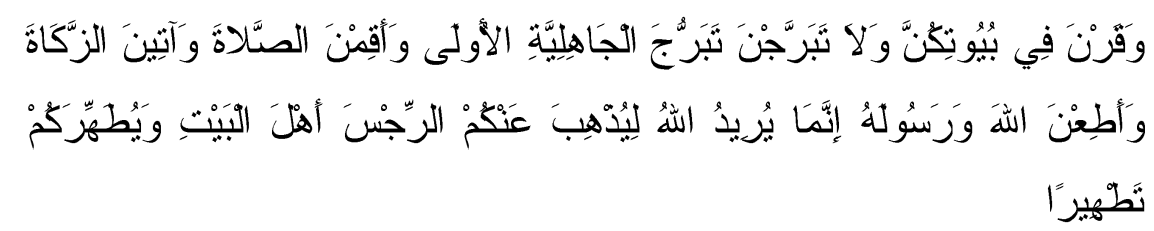

Artinya: "Dan hendaklah kamu tetap diam di rumah kamu serta janganlah kamu mendedahkan diri seperti yang dilakukan oleh orang-orang Jahiliyah zaman dahulu; dan dirikanlah sembahyang serta berilah zakat; dan taatlah kamu kepada Allah dan Rasul-Nya. Sesungguhnya Allah (perintahkan kamu dengan semuanya itu) hanyalah karena hendak menghapuskan perkara-perkara yang mencemarkan diri kamu wahai Ahl al-Bait dan hendak membersihkan kamu sebersihbersihnya (dari segala perkara yang keji)."

Ayat di atas menjelaskan bagaimana seharusnya para isteri Nabi dapat bersikap, yaitu agar mereka dapat menetap di rumah dan tidak berhias seperti berhiasnya orang jahiliyah sehingga orang-orang munafik merasa ingin mengganggu. ${ }^{18}$ Sebagian penafsir membatasi makna berhias itu dengan makna: "keluar dan berjalan di depan banyak laki. ${ }^{19}$ Menurut al-Qurtûbî, sekalipun ayat di atas menunjuk para isteri Nabi, tetapi juga berlaku pada orang mukminah lainnya, sehingga para ibu rumah tangga tidak boleh keluar rumah kecuali dalam keadaan

18al-Suyûthî, Tafsîr al-Jalâlayn (Mesir: Dâr al-Hadis, t.t.), 554.

19al-Shan'ânî, Tafsîr al-Qur'ân, Jilid III (Riyadh: Maktabah al-Rusyd, 1410 H.), 116. 
darurat. ${ }^{20}$ Demikian juga al-Jashashas berpendapat bahwa ayat di atas merupakan perintah kepada perempuan untuk berdiam di rumah dan tidak keluar. ${ }^{21}$ Sementara Ibn al-Arabî berpendapat bahwa larangan keluar bagi perempuan itu dimaksudkan tidak pada yang dibenarkan agama, seperti shalat. ${ }^{22}$ Ada beberapa hadis yang merupakan informasi tentang bagaimana sikap para isteri Nabi Saw. yang dituturkan oleh para perawi, seperti beberapa hadis berikut: ${ }^{23}$

عن محمد بن سيرين قال نبئت انه قيل لسودة زوج النبي صلي الله عليه وسلم

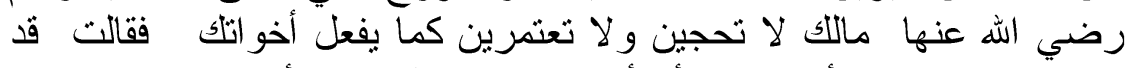

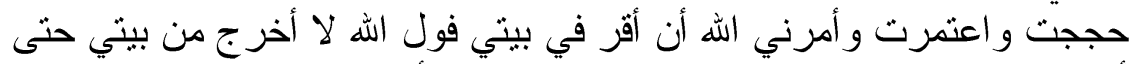

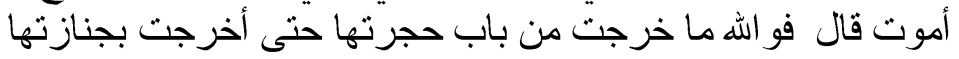

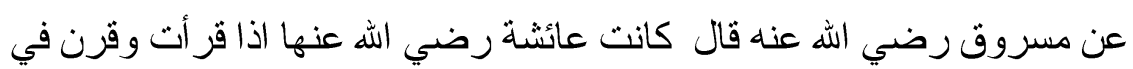
بيو تكن بكت حتى تبل خمار ها لها

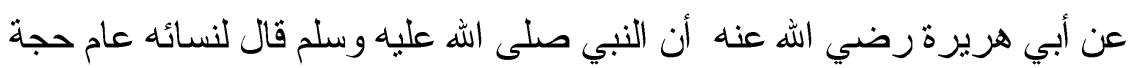

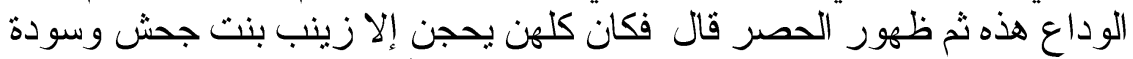
بنت زمعة وكانتا نقو لان و الله لا تحركنا دابة بعد أن سمعنا ذللك من رسول الله صلى الله عليه وسلم

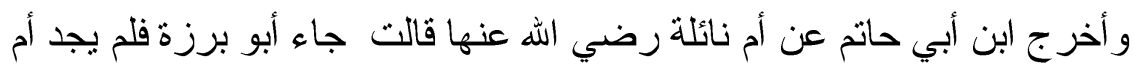

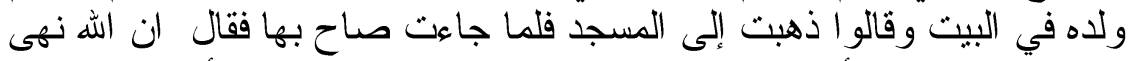

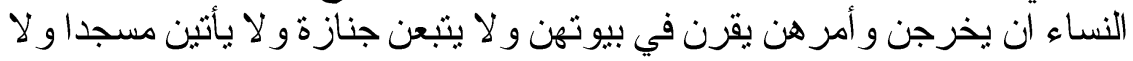

و أخرج البزار عن أنس رضي الله عنه قال جئن النساء إلى رسول الله صلى الله

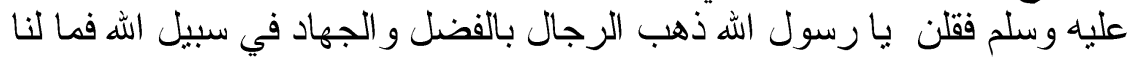

${ }^{20}$ al-Qurthûbî, al-Jami’ lî al-Qur'ân, Jilid XIV (Mesir: Dâr al-Sya'âb, 1372 H.), 179.

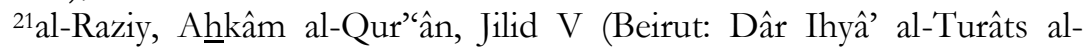
Arabî, 1405 H.), 360.

22M. Quraish Shihab, Wawasan al-Qur'an, Tafsir Maudhu'i Atas Pelbagai Persoalan Umat (Bandung: Mizan, 2000), 304. 600 .

23al-Suyûthî, al-Dur al-Mansyûr, Jilid VII (Beirut: Dâr al-Fikr, 1993), 
عمل ندرك فضل المجاهدين في سبيل الله فقال من قعدث منكن في بيتها فانها تدرك عمل المجاهدين في سبيل الله

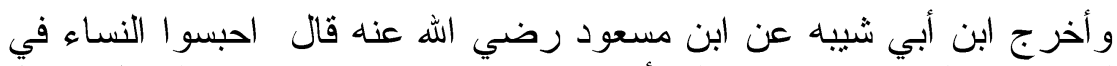

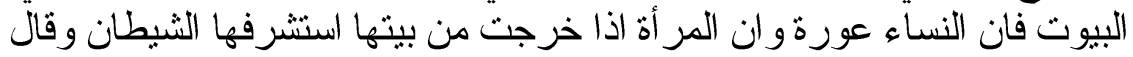

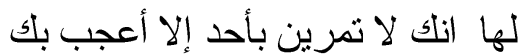
و أخرج التزمذي و البزار عن ابن مسعود رضي الله عنه عن النبي صله الهي الله عليه

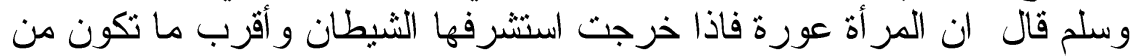

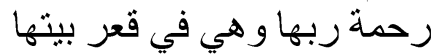

Penafsiran para ulama klasik sebagaimana terurai di atas, menegaskan bahwa ruang lingkup seorang perempuan dalam berkarya tidaklah seluas ruang lingkup kaum Adam yang berkewajiban untuk mencari nafkah. Atas dasar itu, perlulah kiranya kajian yang lebih elaboratif dan humanis terhadap posisi perempuan pada masa kini, minimal untuk mengimbangi kajian ulama klasik yang cenderung masih bersifat "pejoratif".

\section{Catatan Akhir}

Berdasarkan uraian di atas, wajarlah bila opini masyarakat terhadap ruang lingkup tugas perempuan itu ada pada kata dapur, sumur, kasur, dan tidak boleh keluar. Namun, penafsiran ini adalah lebih baik dibanding dengan memberikan kelonggaran yang berlebihan bagi perempuan, yaitu kebolehan perempuan keluar dengan gaya mengumbar keinginan lawan jenis sehingga banyak terjadi hal-hal yang tidak dinginkan. Oleh karena itu para pemikir berusaha mencoba memberikan penafsiran kembali yang lebih ideal dengan ruh-ruh Islam, sehingga keberadaan Islam sebagai rahmat dapat tercermin di dalam segala aspek kehidupan, baik buat laki-laki maupun perempuan.

\section{Daftar Pustaka}

Abu al-A'la al-Maududi, al- $\underline{H} i j a b$ (Dâr al-Fikr, t.t.). 
Abû Ishâq, al-Mabda' fî Syarb al-Muqna', Jilid X (Beirut: al-Maktab al-Islâmî, 1400 H.).

Al-Baehaqî, Sunan al-Baehaqî al-Kubra, Jilid VII (Makkah alMukarramah: Maktabah Dâr al-Bar, 1994).

Al-Baidlawî, Tafsîr al-Baidlawî (Beirut: Dâr al-Fikr, 1996).

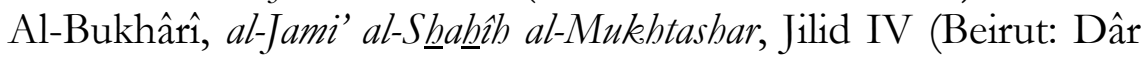
Ibn Katsîr, 1987).

\section{, Shahîh al-Bukhârî (Beirut: Dâr al-Fikr, t.t.).}

Al-Jawzî, Zad al-Masir fî Tlm al-Tafsîr (Beirut: al-Maktab al-Islâmî, 1404 H.).

Al-Nasâfî, Al-Nasâfî (t.tp.: t.np, tt).

Al-Qurthûbî, Al-Jami' lî al-Qur'ân, Jilid XIV (Mesir: Dâr alSya"âb, 1372 H.).

Al-Raziy, Abkeâm al-Qur'ân, Jilid V (Beirut: Dâr Ihyâ' al-Turâts alArabî, 1405 H.).

Al-Shabûnî, Shafwah al-Tafâsir (Beirut: Dâr al-Fikr, t.t.).

Al-Shan'ânî, Tafsîr al-Qur'ân, Jilid III (Riyadh: Maktabah alRusyd, 1410 H.).

Al-Suyûthî, al-Dur al-Mansyûr, Jilid II dan VII (Beirut: Dâr alFikr, 1993).

\section{, Tafsîr al-Jalâlayn (Mesir: Dâr al-Hadîst, t.t.).}

Al-Thabârî, Jami' al-Bayân 'an Ta'wîl Ayyâh al-Qur'ân (Beirut: Dâr al-Fikr, 1405 H.).

Al-Thabathabâ'î, Al-Mizâan fì Tafsîr al-Qur'ân (Beirut: Muassasah li al-'Alâmî, 1983).

Al-Turmudzî, Sunan al-Turmudzî̀ (Beirut: Dâr Ihyâ' al-Turâst alArabî, t.t.).

Al-Wahîdî, Al-Wajî̀ fî̀ Tafsîr al-Kitâb al-'Azî̀z (Beirut: Dâr alSyâmiyah, $1415 \mathrm{H}$ ).

Ibn al-Manzhûr, Lisân al-'Arab, Jilid XII (Beirut: Dâr al-Shadir, t.t.).

Ibn Katsîr, Tafsîr al-Qur'an al-Az̧hîm (Beirut: Dâr al-Fikr, 1401 H.).

Ibn Mâjah, Sunan Ibn Mâjah (Beirut: Dâr al-Fikr, t.t.). 


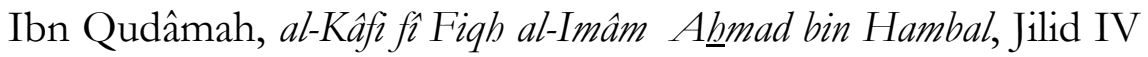
(Beirut: al-Maktab al-Islâmî, 1988).

Ibrâhîm bin Muhammad bin Salim bin Dhuyan, Manâr al-Sabîl, Jilid III (Riyadh: Maktab al-Ma'ârif, 1405 H.).

Idrîs al-Buhtî, Kisyaf al-Iqnâ' 'an Matn al-Iqnâ (Beirut: Dâr al-Fikr, $1405 \mathrm{H}$.$) .$

Kiyâ Harâsi, Ablkâm al-Qur'ân (Beirut: Dâr al-Kutub al-Ilmiyah, 1985).

M. Quraish Shihab, Wawasan al-Qur'an, Tafsir Maudhu'i atas Pelbagai Persoalan Umat (Bandung: Mizan, 2000). , Tafsir al-Mishbah (Jakarta: Lentera Hati, 2000).

Muhammad al-Lûsî, Rûh al-Ma'ânî fi Tafsîr al-Qur'ân al-Az̧bim wa al-Saba' al-Mastanî (Beirut: Dâr Ihyâ' al-Turâst al-'Ârabî, t.t.).

Muslim, S $\underline{h}$ ahîh Muslim (Beirut: Dâr al-Fikr, t.t.).

Said Agil Husen al-Munawar, Al-Qur'an Membangun Tradisi Kesalehan Hakiki (Jakarta: Ciputat press, 2002).

Sayyid Quthb, Fî̀ Dŗhilâl al-Qur'ân, Jilid IV (Beirut: Dâr al-Fikr, 1987).

Sayyid Sabbiq, Fiqh al-Sunnah, Jilid II (Beirut: Dâr al-Fikir, 1992).

Syihâb al-Dîn Abî al-Fadhal Ahmad bin 'Âlî, Al-Ajab fì Bayân alAsbâb, Jilid II (Beirut: Dâr Ibn al-Jawzy, 1997). 